\title{
Didemnins Inhibit COVID-19 Main Protease (Mpro)
}

\author{
Selmihan Sahin 1,*iD , Furkan Calapoğlu ${ }^{1} \stackrel{(D)}{ }$, Ismail Ozmen ${ }^{1}$ (D) \\ 1 Suleyman Demirel University, Arts and Sciences Faculty, Department of Chemistry, Cunur, Isparta, 32260, Turkey \\ * Correspondence: selmihansahin@sdu.edu.tr
}

Scopus Author ID 56511235900

Received: 1.07.2020; Revised: 18.07.2020; Accepted: 19.07.2020; Published: 22.07.2020

\begin{abstract}
The novel coronavirus disease because of infection with the SARS-CoV-2 virus, COVID19, was first appeared in Wuhan, China, in December 2019. It has spread rapidly all around the World and has been accepted as a pandemic. Specific therapies for COVID-19 treatment is not available for now. Thus, there is a huge effort to develop and discover new therapeutic agents and vaccines by scientists. The design and development of new therapeutic agents for treatment through medicinal chemistry is slow and needed a hard labor process. Thus, it is urgent to achieve the discovery of more effective agents. Marine natural products have antiviral activity and quite significant pharmacological capacity. The antiviral properties of these products are shown as new promising therapeutic alternatives against the viruses. The present work aimed to assess the inhibition potential of Didemnin A, B, and C isolated from tunicates to COVID-19 Mpro protein through a molecular docking method. The molecular characterization of compounds with binding affinity was performed by using the Swiss Target Prediction Method. As a result, the binding energy of Didemnins A, B, and C was calculated as -11.82 $\mathrm{kcal} / \mathrm{mol},-10.27 \mathrm{kcal} / \mathrm{mol}$, and $-9.26 \mathrm{kcal} / \mathrm{mol}$, respectively. Also, the docking studies showed that Didemnin B involved in hydrogen bonding with Glu166 in the active site of the Mpro protein. Therefore, the natural marine compounds have the potential for developing drugs against to SARSCoV-2 virus, which may aid in overcoming the clinical challenge of the COVID-19 pandemic.
\end{abstract}

Keywords: COVID-19; Didemnin; Protease; Inhibition; Docking.

(C) 2020 by the authors. This article is an open-access article distributed under the terms and conditions of the Creative Commons Attribution (CC BY) license (https://creativecommons.org/licenses/by/4.0/).

\section{Introduction}

The recent outbreak of coronavirus disease 2019 (COVID-19) has rapidly spread to almost all countries after the first detection in Wuhan, China, in December of 2019. There are over 11,000 000 confirmed cases and over 524000 confirmed deaths worldwide, so far [1-3].

Coronaviruses (CoVs) contain a positive-sense single-stranded RNA enveloped with a membrane. Humans and other mammalian hosts can be infected by many of the CoVs. There are four groups of CoVs designated as alpha, beta, gamma, and delta. Alpha and beta CoVs are known to infect humans $[1,2]$. SARS-CoV-2 is in the beta CoVs class, which also includes the most aggressive strains of Coronavirus Severe Acute Respiratory Syndrome (SARS) Virus (SARS-CoV), Middle East Respiratory Syndrome [4] Virus (MERS-CoV) [1, 5, 6]. All these virus attacks to the lower respiratory system besides the heart, gastrointestinal system, central nervous system, kidney, and liver may also be affected. However, there is no clinically approved antiviral drug for coronavirus treatment [1]. Although there are currently ongoing clinical studies on COVID-19 with different existing drugs (Remdisivir, Favilavir, etc.) (https://ghddi-ailab.github.io/Targeting2019-nCoV/clinical/), it is still critical and urgent to search for other effective inhibitors for the potential treatment of COVID-19 [2]. 
The genome analysis of Coronavirus revealed the presence of structural and nonstructural proteins. They are responsible for transcription, translation, synthesis, processing, and modification of RNA, virus replication, and infection. Among these, 3-Chymotrypsin-Like protease (Mpro, also called 3CLpro), Papain Like protease (PLpro), RNA-dependent RNA polymerase $(\mathrm{RdRp})$, and helicase are the most important targets for the development of inhibitors [7]. This study focused on Mpro protein in CoVs as potential target proteins to treat COVID-19. Mpro is active in its dimer state, but till now, its crystal structure is not available for the dimer form. Mpro's monomer form consists of the 306 amino acids with three domains, folded into helices and $\beta$-strands. The monomeric form of Mpro has been successfully crystallized from COVID-19 with N3 peptide-like molecule by Liu et al. [8]. It has been structured and repositioned in the Protein Data Bank (PDB) and is accessible by the public (PDB-ID: 6LU7). This protease represents a potential target for the inhibition of $\mathrm{CoV}$ replication [9].

Natural products have contributed most of the therapeutic agents in use today, especially in antibiotics and chemotherapy agents $[10,11]$. The studies have shown that the natural product of marine origin has unique chemical structures and new cellular targets and modes of actions, which are bringing significant innovation to the field as a therapeutic agent [12]. Didemnins A, B, and C are marine depsipeptides isolated from tunicates or sea squirts of the family Didemnidae. At low nano- and femtomolar levels, their antiviral activities have been shown.. Among them, didemnin B (a derivative of didemnin A) reached to phase II as the first marine natural product. It inhibits viral replication in vitro at the lowest concentration $[13,14]$.

Compared with laboratory techniques, molecular docking methods provide to assign compounds with their potential inhibitor effects by predicting their structure and design effective drugs rapidly and with a high-throughput approach. After the prediction of compounds through such computational methods, it is necessary to approve them via classic experimental procedures. Also, these methods provide a selection of the most convenient compounds for treatment by saving time [7, 15-17].

Considering the emergency situation, in this study, a molecular docking study was conducted to determine the potential of Didemnins (A, B, and C) as an inhibitor for Mpro against to COVID-19.

\section{Materials and Methods}

\subsection{Molecular analysis protocol.}

Interaction between Protein and ligand, type of binding and binding affinity of Mpro protease with didemnins were determined via the docking method

\subsection{Proteins.}

The file of the COVID-19 Mpro (PDB ID: 6LU7) was obtained from Protein Data Bank (PDB) (https://www.rcsb.org/). The 6LU7 protein is a homodimer and contains 306 amino acid residues, and two chains, named as A and B. Chain A was used for macromolecule preparation. Water molecules were removed, and nonpolar hydrogen molecules were added to the protein structure in Python molecule viewer setting of mgltools (http://mgltools.scripps.edu/). 


\subsubsection{Ligands.}

CID files and molecular ligand data were obtained from PubChem on the NCBI database (https://pubchem.ncbi.nlm.nih.gov/search/search.cgi) (Table I). Ligands were converted to mol2 format in Open Babel (https://openbabel.org/) GUI 2.3.2a setting.

\subsection{Protein-ligand docking.}

Docking was performed in Swiss Target Prediction (http://www.swissdock.ch/) to predict interactions between ligands and proteins.

\subsection{Analysis.}

Results were viewed and analyzed with chimera 1.14(https://www.cgl.ucsf.edu)

\section{Results and Discussion}

COVID-19 virus Mpro (PDB ID: 6LU7) has been studied by Didemnin A, B, and C molecules to predict capability inhibition of this enzyme activity and, consequently, the reproduction of the virus. The protein structure and the chemical structure of the studied ligand molecules (Didemnin A, B, and C) are shown.
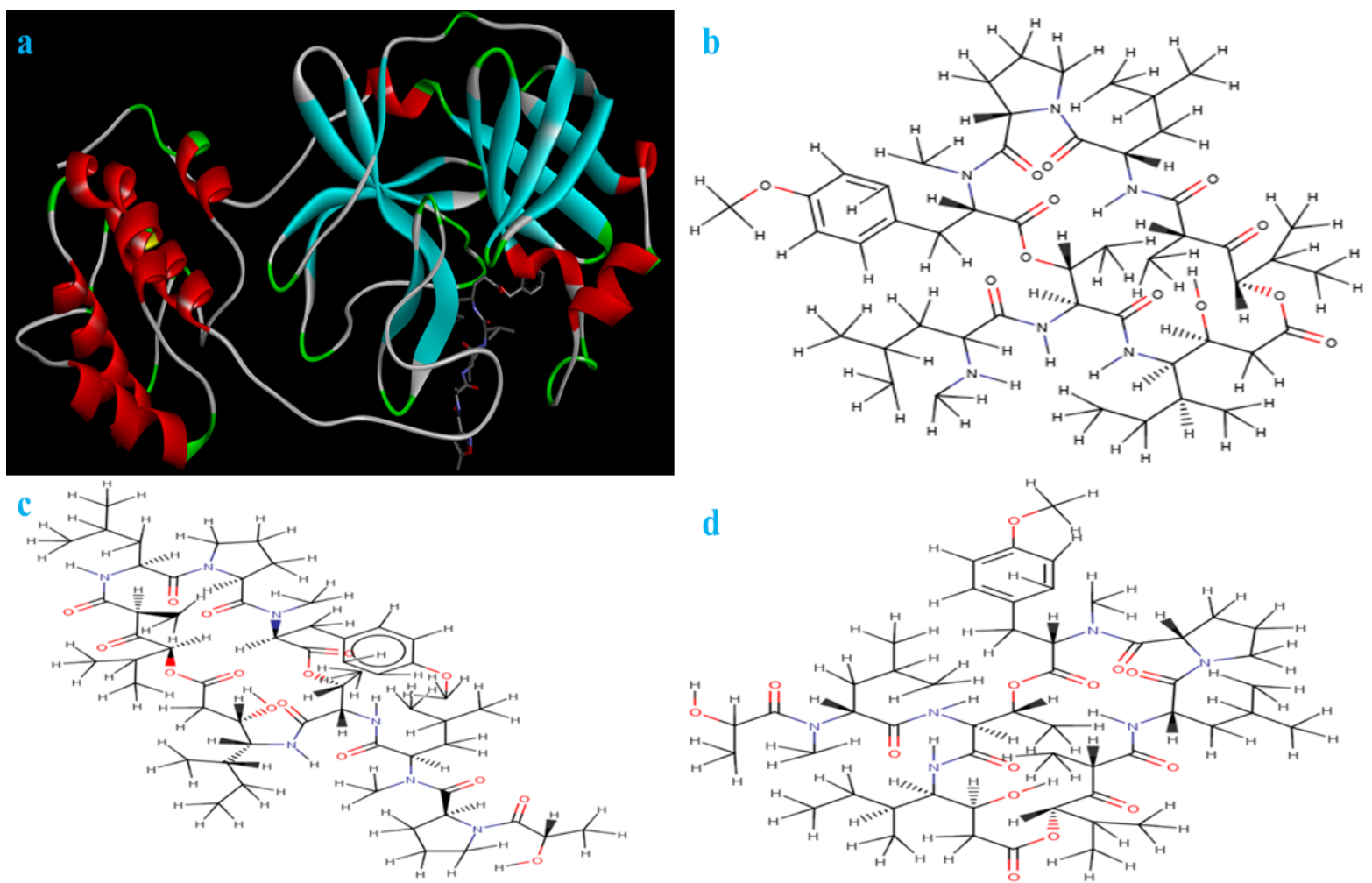

Figure 1. Ribbon diagram of the COVID-19 Mpro in the complex with an inhibitor N3 (a). Chemical structures of the Didemnin A (b), B (c), C (d).

To understand the binding interaction of Didemnin A, B, and C molecules with Mpro, Swiss Target Prediction (http://www.swissdock.ch/) was used. In order to assess the accuracy of Swiss Target Prediction, the co-crystallized ligand (N3) was removed from the active site and docked within the inhibitor binding cavity of Mpro protease. Thr24, Thr26, Phe140, Asn142, Gly143, Cys145, His163, His164, Glu166, His172 are predicted active site residues (Biovia Discovery Studio 4.5, 2019) in the previous study by Khaerunnisa et al. [9]. 


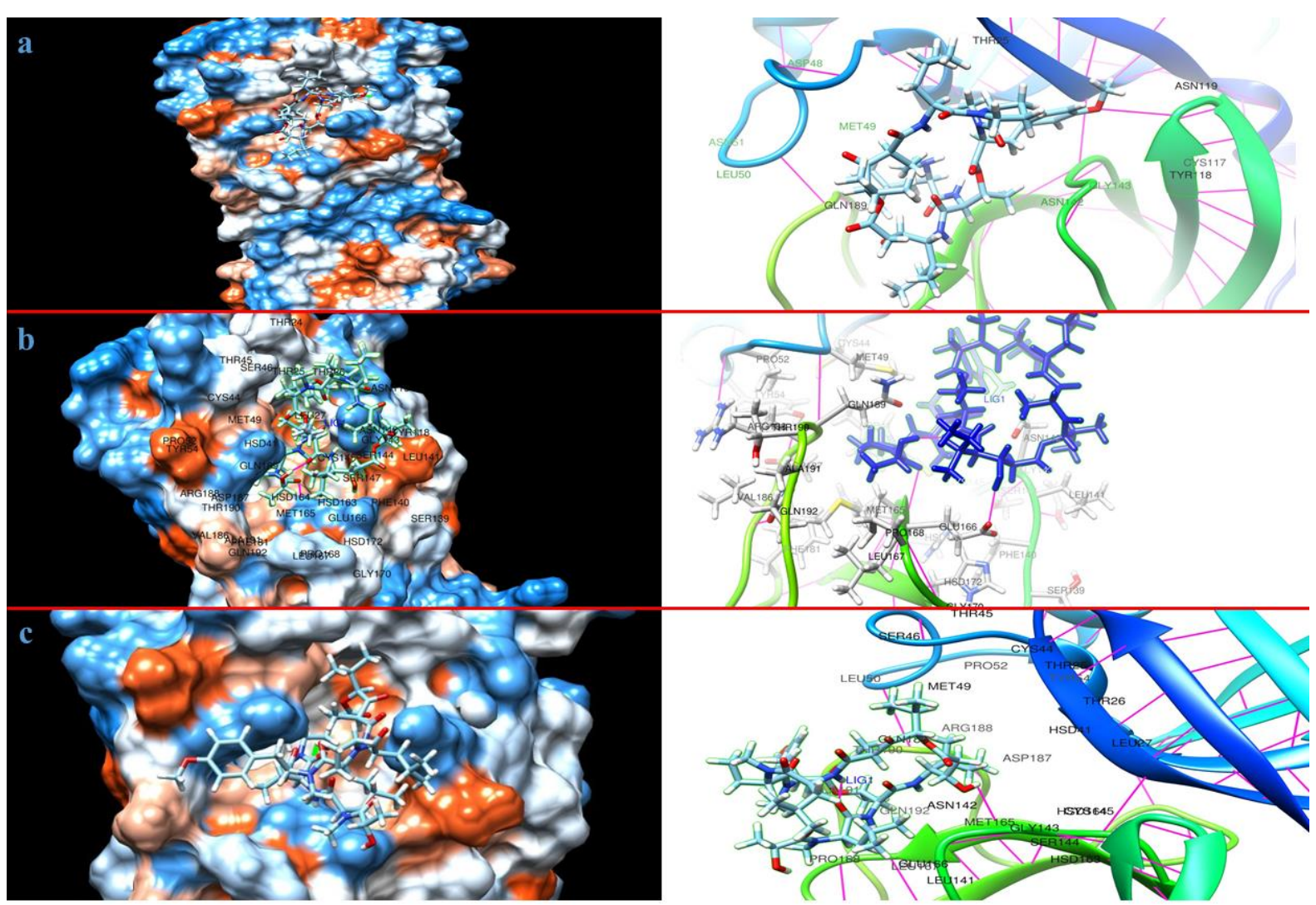

Figure 2. Docking of Didemnin A (a), B (b), and C (c) into the active site of 6LU7. Docking interaction of Didemnins with the active site of 6LU7 (left), Docking interactions of amino acids with Didemnins (right).

Table 1. Molecular docking analysis of Didemnins (A, B, and C) and native ligand against 6LU7.

\begin{tabular}{|c|c|c|c|}
\hline Protein & Ligands & $\begin{array}{c}\text { Estimated } \Delta G \\
\quad(\mathrm{kcal} / \mathrm{mol})\end{array}$ & $\begin{array}{c}\text { Molecular weight } \\
(\mathrm{g} / \mathrm{mol})\end{array}$ \\
\hline \multirow{4}{*}{ 6LU7 } & Native ligands (N3) & -9.22 & 681 \\
\hline & Didemnin A & -11.82 & 943.2 \\
\hline & Didemnin B & -10.27 & 1112.4 \\
\hline & Didemnin C & -9.26 & 1015.2 \\
\hline
\end{tabular}

These residues play an important role in binding and catalytic activity in the active site of Mpro. The docking interactions between the binding site residues and the Didemnin A, B, and $\mathrm{C}$ molecules with their respective binding energy were given in Fig. $2 \mathrm{a}-\mathrm{d}$ and Table 1 . In this study, the binding energy of the N3 inhibitor to the Mpro was found as $-9.22 \mathrm{kcal} / \mathrm{mol}$, showing that our docking method is valid for the studied inhibitors. The results indicated that Didemnins (A, B, and C) have a relatively high affinity to the active site of Mpro (Table 1). The docking interaction of the Didemnin A with the COVID 19 Mpro was calculated as -11.82 $\mathrm{kcal} / \mathrm{mol}$ while the Didemnin B and C are found to be docked with $-10.27 \mathrm{kcal} / \mathrm{mol}$ and -9.26 $\mathrm{kcal} / \mathrm{mol}$, respectively. Conspicuously, their binding energy was higher when compared with native inhibitor (N3). It was observed lower binding energy to the COVID-19 Mpro with promising drug targets, plant compounds in the early studies [2, 5, 9, 18, 19]. The binding energies obtained from the docking of 6LU7 with nelfinavir [9], diosmin [19] were -10.72, and $10.1 \mathrm{kcal} / \mathrm{mol}$, respectively. Pant et al. reported that peptide-like molecules could be an alternative to the small molecule as an inhibitor to the COVID-19 Mpro because of their flexibility. This provides them to fit comfortably inside the binding site. Also, they are less toxic and easy to synthesize [20]. It was reported that isonicotinoyl hydrazide derivatives could be an effective Mpro inhibitor [21]. It can be said that Didemnins have more advantages than other drugs as a Mpro inhibitor to treat COVID-19 due to their peptide structure. 
Furthermore, it is observed that the amino acid Glu166 in the catalytic site bonded to the Didemnin B by the formation of $\mathrm{H}$ bonds. Thus, Didemnin B can be a more effective inhibitor to the Mpro because this residue plays an important role in the enzymatic hydrolysis.

\section{Conclusions}

As conclusion, Didemnin A, B, and C tightly bind to COVID-19 Mpro protein, and thus, we can say that they are acting as a potent inhibitor against Mpro activity of the viral enzyme and thereby the SARS-CoV-2 viral replication. Further studies about these marine nature compound able to stop the newly emerged COVID-19 infection.

\section{Funding}

This research received no external funding.

\section{Acknowledgments}

This research has no acknowledgment.

\section{Conflicts of Interest}

The authors declare no conflict of interest.

\section{References}

1. $\quad$ Liu, C.; Zhou, Q.; Li, Y.; Garner, L.V.; Watkins, S.P.; Carter, L.J.; Smoot, J.; Gregg, A.C.; Daniels, A.D.; Jervey, S.; Albaiu, D. Research and Development on Therapeutic Agents and Vaccines for COVID-19 and Related Human Coronavirus Diseases. ACS Central Science 2020, 6, 315-331, https://doi.org/10.1021/acscentsci.0c00272.

2. Xu, J.; Shi, P.-Y.; Li, H.; Zhou, J. Broad Spectrum Antiviral Agent Niclosamide and Its Therapeutic Potential. ACS Infectious Diseases 2020, 6, 909-915, https://doi.org/10.1021/acsinfecdis.0c00052.

3. Liu, J.; Liao, X.; Qian, S.; Yuan, J.; Wang, F.; Liu, Y.; Wang, Z.; Wang, F.-S.; Liu, L.; Zhang, Z. Community Transmission of Severe Acute Respiratory Syndrome Coronavirus 2, Shenzhen, China, 2020. Emerging Infectious Disease journal 2020, 26, https://doi.org/10.3201/eid2606.200239.

4. Reis, C.; Sousa, E.; Serpa, J.; Oliveira, R.; Oliveira, J. Santos. Design of Immobilized Enzyme Biocatalysts: Drawbacks and Opportunities. Química Nova 2019, https://doi.org/10.21577/0100-4042.20170381.

5. Elfiky, A.A. Anti-HCV, nucleotide inhibitors, repurposing against COVID-19. Life Sci 2020, 248, https://doi.org/10.1016/j.lfs.2020.117477.

6. Huang, R.; Zhao, H.; Wang, J.; Yan, X.; Shao, H.; Wu, C. A family cluster of COVID-19 involving an asymptomatic case with persistently positive SARS-CoV-2 in anal swabs. Travel Medicine and Infectious Disease 2020, https://doi.org/10.1016/j.tmaid.2020.101745.

7. Teixeira de Oliveira, K.M., M.D. Lima de Oliveira. Comparative Computational Study of SARS-CoV-2 Receptors Antagonists from Already Approved Drugs. ChemRxiv. Preprint. https://doi.org/10.26434/chemrxiv.12044538.v1.

8. Liu, X.; Zhang, B.; Jin, Z.; Yang, H.; Rao, Z. The crystal structure of COVID-19 main protease in complex with an inhibitor N3. RSCB PDB, pdbode: 6LU7. 2020. https://doi.org/10.1101/2020.02.26.964882.

9. Khaerunnisa, S.; Kurniawan, H.; Awaluddin, R.; Suhartati, S.; Soetjipto, S. Potential Inhibitor of COVID19 Main Protease (Mpro from Several Medicinal Plant Compounds by Molecular Docking Study. Pre Print 2020, https://doi.org/10.20944/preprints202003.0226.v1.

10. Potts, M.B.; McMillan, E.A.; Rosales, T.I.; Kim, H.S.; Ou, Y.-H.; Toombs, J.E.; Brekken, R.A.; Minden, M.D.; MacMillan, J.B.; White, M.A. Mode of action and pharmacogenomic biomarkers for exceptional responders to didemnin B. Nature Chemical Biology 2015, 11, 401-408, https://doi.org/10.1038/nchembio.1797.

11. Yu, R.; Chen, L.; Lan, R.; Shen, R.; Li, P. Computational screening of antagonists against the SARS-CoV2 (COVID-19) coronavirus by molecular docking. International Journal of Antimicrobial Agents 2020, https://doi.org/10.1016/j.ijantimicag.2020.106012. 
12. Jimenez, P.C.; Wilke, D.V.; Branco, P.C.; Bauermeister, A.; Rezende-Teixeira, P.; Gaudêncio, S.P.; CostaLotufo, L.V. Enriching cancer pharmacology with drugs of marine origin. British Journal of Pharmacology 2020, 177, 3-27, https://doi.org/10.1111/bph.14876.

13. Lee, J.; Currano, J.N.; Carroll, P.J.; Joullié, M.M. Didemnins, tamandarins and related natural products. Natural Product Reports 2012, 29, 404-424, https://doi.org/10.1039/c2np00065b.

14. Rinehart, K.L.; Gloer, J.B.; Hughes, R.G.; Renis, H.E.; McGovren, J.P.; Swynenberg, E.B.; Stringfellow, D.A.; Kuentzel, S.L.; Li, L.H. Didemnins: antiviral and antitumor depsipeptides from a caribbean tunicate. Science 1981, 212, 933-935, https://doi.org/10.1126/science.7233187.

15. Sadati, S.M.; Gheibi, N.; Ranjbar, S.; Hashemzadeh, M.S. Docking study of flavonoid derivatives as potent inhibitors of influenza H1N1 virus neuraminidase. Biomed Rep 2019, 10, 33-38, https://doi.org/10.3892/br.2018.1173.

16. Cheke, R.S. The Molecular Docking Study of Potential Drug Candidates Showing Anti-COVID-19 Activity by Exploring of Therapeutic Targets of SARS-CoV-2. Eurasian Journal of Medicine and Oncology 2020, https://doi.org/10.14744/ejmo.2020.31503.

17. Mishra, A.; Dey, S. Molecular Docking Studies of a Cyclic Octapeptide-Cyclosaplin from Sandalwood. Biomolecules 2019, 9, https://doi.org/10.3390/biom9110740.

18. Chen, Y.W.; Yiu, C.B.; Wong, K. Prediction of the SARS-CoV-2 (2019-nCoV) 3C-like protease (3CL ) structure: virtual screening reveals velpatasvir, ledipasvir, and other drug repurposing candidates. F1000Research 2020, 9, 1-13, https://doi.org/10.12688/f1000research.22457.1.

19. Wong, K.Y.; Yiu, C.P.; Chen, Y.W. Prediction of the 2019-nCoV 3C-like Protease (3CLpro) Structure: Virtual Screening Reveals Velpatasvir, Ledipasvir, and Other Drug Repurposing Candidates. ChemRxiv. Preprint 2020, https://doi.org/10.26434/chemrxiv.11831103.v1.

20. Pant, S.; Singh, M.; Ravichandiran, V.; Murty, U.S.N.; Srivastava, H.K. Peptide-like and small-molecule inhibitors against Covid-19. Journal of Biomolecular Structure and Dynamics 2020, 1-15, https://doi.org/10.1080/07391102.2020.1757510.

21. Hosny, N.M., Y. Sherif. Molecular Docking Study on Some Isonicotinoyl Hydrazide Derivatives as Potential Inhibitors of COVID19. Letters in Applied NanoBioScience 2020, 9(3), 1217- 1224. doi:10.33263/LIANBS93.12171224. 